\title{
Engineered IGF-I expression induces glandular enlargement in the murine prostate
}

\author{
N Konno-Takahashi, T Takeuchi, T Shimizu, H Nishimatsu, \\ H Fukuhara, T Kamijo, N Moriyama, S Tejima ${ }^{1}$ and $\mathbf{T}$ Kitamura \\ Department of Urology and Andrology, Faculty of Medicine, University of Tokyo, 7-3-1 Hongo, Bunkyo-ku, Tokyo, Japan 113-8655 \\ ${ }^{1}$ Pathologic Division, Douai Memorial Hospital, 2-1-11 Yokozuna, Sumida-ku, Tokyo 130-8587 \\ (Requests for offprints should be addressed to Takumi Takeuchi; Email: nezu-tky@umin.ac.jp)
}

\begin{abstract}
IGF-I has been implicated as a factor that may predispose one to prostate cancer and to benign prostatic hypertrophy $(\mathrm{BPH})$. We established murine IGF-I transgenic mice under the control of rat probasin promoter and analysed the histology of the murine IGF-I-overexpressing prostate.

Immunohistochemically, IGF-I was expressed in prostatic epithelial cells or basement membranes of the ventral, dorsal and lateral lobes in a line of IGF-I transgenic mice, but not in their control littermates. The anterior lobe did not express IGF-I. IGF-binding protein-3 (IGFBP-3), inhibitory to the mitogenic action of IGF-I, was detected in epithelial cells of prostatic ventral lobes, but not in those of the dorsal, lateral or anterior lobes of IGF-I transgenic mice. In controls, IGFBP-3 was not detected in epithelial cells of any prostatic lobe. Macroscopic prostatic size and the appearance of IGF-I transgenic mice were comparable with those of their control littermates of the same age. With a computed morphometric analysis, epithelial glands and intraglandular lumens in the prostatic lobes except the
\end{abstract}

ventral lobe were smaller at 17 months of age than at 14 months both in IGF-I transgenic mice and controls. Glands and intraglandular lumens in the ventral prostatic lobes of IGF-I transgenic mice expressing more IGF-I protein in the prostate than controls were dense and enlarged similar to cysts compared with those of nontransgenic littermates without showing epithelial growth. Glands and lumens in the dorsal and lateral lobes of the IGF-I transgenic mice were also larger than controls at 14 and/or 17 months of age. Glands in the anterior prostatic lobe of the IGF-I transgenic mice were not morphologically or morphometrically different from those of non-transgenic littermates.

In conclusion, IGF-I transgenic mice under the control of rat probasin promoter showed more dense and enlarged epithelial glands in their prostatic ventral, dorsal and lateral lobes.

Journal of Endocrinology (2003) 177, 389-398

\section{Introduction}

Insulin-like growth factors IGF-I and IGF-II are $7 \mathrm{kDa}$ mitogenic polypeptides involved in the regulation of cell proliferation, differentiation and apoptosis. There are two transmembrane IGF receptors, both of which have a similarity to the insulin receptor (Djavan et al. 2001). The type 1 IGF receptor (IGF-1R) is expressed in prostatic epithelial and stromal cells (Djavan et al. 2001). The IGF-binding proteins (IGFBPs) 1-6 were reported to be involved in the modulation of the proliferative and mitogenic effects of IGFs on cells. Most IGF-I and IGF-II $(99 \%)$ are bound to IGFBPs in serum. The interaction of IGF-I and IGF-II with IGF-1R is regulated by IGFBPs, which are expressed by prostatic epithelial cells and to a lesser extent by stromal cells (Djavan et al. 2001). IGFBP-3 decreases the mitogenic effects of IGF-I in normal prostate epithelial cells in culture, and cleavage of the binding protein by prostate-specific antigen decreases its affinity for IGF-1R, thus reversing this inhibitory effect (Djavan et al. 2001).

IGF-I has been implicated as a factor that may predispose one to prostate cancer and to benign prostatic hypertrophy (BPH). In humans, elevated serum IGF-I was reported to be a potent risk factor of carcinogenesis of the prostate (Chan et al. 1998). Glands from 44-day-old IGF-I-deficient animals were not only smaller than those from wild-type mice, but also had fewer terminal duct tips and branch points, and deficits in tertiary and quaternary branching, indicating a specific impairment in gland structure (Ruan et al. 1999). In the transgenic adenocarcinoma of the mouse prostate model (TRAMP) that expresses SV40 T antigen specifically in the epithelium of the prostate, prostate-specific IGF-I and fibroblast growth factor-2 (FGF-2) axis mRNA expression increased during prostatic cancer progression similar to the accompanying 
metastatic lesions (Foster et al. 1998, Kaplan et al. 1999). Both prolactin and growth hormone transgenic mice elevated IGF-I levels, the former developed marked prostatic enlargement while the latter showed slight enlargement, thus the direct action of IGF-I on prostatic growth is still controversial (Wennbo et al. 1997).

It is necessary to introduce IGF-I in the prostate epithelium to delineate the prostatic growth induced by IGF-I. Recently, DiGiovanni et al. (2000) reported that IGF-I transgenic mice under the control of BK5 promoter expressing human IGF-I in the basal epithelium of mouse prostate formed spontaneous neoplasia in the tissue. We have also established murine IGF-I transgenic mice under the control of rat probasin promoter and analysed the histology of the murine IGF-I-overexpressing prostate. Probasin (prostate basic protein) is an androgen-dependent and prostate-specific secretory protein produced in differentiated prostatic epithelial cells. Short rat probasin promoter $(-426$ to +34$)$ is used to establish transgenic mice expressing genes in the prostatic epithelial cells (Rennie et al. 1993).

\section{Materials and Methods}

\section{Construction of murine IGF-I expression vector}

pBH500 vector containing the $5^{\prime}$-flanking region of the rat probasin gene was digested with HindIII, blunted with Klenow DNA polymerase, digested with BamHI, then electrophoresed. The $454 \mathrm{bp}$ fragment of pBH500 including the rat probasin promoter region was gel-purified, and ligated between the KpnI site blunted with Klenow and the cohesive BamHI site of the pUC18 vector, resulting in the pUC18-probasin vector. Murine IGF-I cDNA was excised with EcoRI from pmigf1 purchased from the American Tissue Culture Collection, gel-purified, and ligated into the EcoRI site of the mammalian expression vector pCAGGS (Niwa et al. 1991) yielding pCmIGFI. The XbaI-HindIII fragment of pCmIGF1, containing murine IGF-I cDNA and the rabbit $\beta$-globin polyA signal, was ligated between the $\mathrm{XbaI}$ and HindIII sites of pUC18-probasin, yielding the pBH-IGFI vector, which expresses murine IGF-I under the control of rat probasin promoter.

\section{Establishment of murine IGF-I transgenic mice}

Transgenic mouse lines were generated by microinjection of fertilized eggs as described previously (Takeuchi et al. 1999). The purified inserts of the SacI-HindIII fragment of pBH-IGF1 were injected into the male pronucleus of fertilized eggs from the C57BL/6 L (Japan SLC, Inc., Hamamatsu, Japan) mouse strain. The manipulated eggs were cultured and transferred into the oviducts of ICR mice (Japan SLC, Inc.) pseudopregnant recipients. New- born mice and their descendants were screened for genomic integration of the murine IGF-I transgene as described below. Tail genomic DNA purified as described previously (Takeuchi et al. 1999) was amplified by 35 cycles $\left(95{ }^{\circ} \mathrm{C}\right.$ for denaturing, $55^{\circ} \mathrm{C}$ for annealing and $72{ }^{\circ} \mathrm{C}$ for extension) of PCR, using a thermal cycler with $1 \mathrm{mM}$ sense and antisense primers (5'-CAGGCATTG GGCATTGTCCA-3'/5'-CTCGGTCCACACACGAA CTG-3') taken from the rat probasin promoter region upstream from the inserted cDNA and murine IGF-I cDNA respectively, $10 \mathrm{mM}$ dNTPs, $2.5 \mathrm{U}$ of Taq polymerase (Roche Diagnostics Corp.), and the buffer supplied with the enzyme. Amplified products $(10 \mu \mathrm{l})$ were resolved by electrophoresis in $1.5 \%$ agarose gels containing ethidium bromide. Transgene-positive founder (F0) mice (C57BL/6 L) were crossed with naive C57BL/ $6 \mathrm{~L}$ and naive $\mathrm{C} 3 \mathrm{H} / \mathrm{HeN}$ mice (Nihon Clea, Tokyo, Japan). The studies were approved by the authors' institutional committees on animal care.

\section{RT-PCR}

RT-PCR was performed as described previously (Takeuchi et al. 1999) using $2 \mu \mathrm{g}$ of total RNA. Sense/antisense PCR primer for murine IGF-I and $\beta$-actin were $5^{\prime}$-TCGTCT TCACACCTCTTCTACCTGG-3'/5'-TGCTTTTGTA GGCTTCAGTGGGGCA- $3^{\prime}$ and $5^{\prime}$-TGGAATCCTGT GGCATCCATGGAAAC- $3^{\prime} / 5^{\prime}$-TAAAACGCAGCTCA GTAACAGTCCG-3' respectively.

\section{Western blotting}

Protein was extracted from IGF-I transgenic and control F1 (C57BL/6 L $\times \mathrm{C} 3 \mathrm{H} / \mathrm{HeN})$ prostates in a Triton $\mathrm{X}-100$ homogenization buffer containing $1 \mathrm{mmol} / 1 \mathrm{PMSF}$, $2 \mu \mathrm{g} / \mathrm{ml}$ leupeptin, and $2 \mu \mathrm{g} / \mathrm{ml}$ aprotinin. After centrifugation for $20 \mathrm{~min}$ at $4{ }^{\circ} \mathrm{C}$, the cleared supernatant was used for immunoprecipitation. Three hundred micrograms of each protein extract were pre-cleaned with protein $\mathrm{A}$ agarose beads (Roche Diagnostics Corp.) for $1 \mathrm{~h}$ at $4{ }^{\circ} \mathrm{C}$ in the Triton-X 100 cell lysis buffer. The extracts were then incubated with $2 \mu \mathrm{g}$ anti-IGFI antibody for $1 \mathrm{~h}$ at $4{ }^{\circ} \mathrm{C}$ and with protein $\mathrm{A}$ agarose beads for another hour at $4{ }^{\circ} \mathrm{C}$ with constant rocking. After centrifugation, the pellets were washed twice with the Triton-X cell lysis buffer and then three times with a kinase buffer (50 mmol/1 Tris-HCl, $\mathrm{pH} 8.0,10 \mathrm{mmol} / 1 \quad \mathrm{MgCl}_{2}$, $1 \mathrm{mmol} / 1$ dithiothreitol, $1 \mathrm{mmol} / 1 \mathrm{PMSF}, 2 \mu \mathrm{g} / \mathrm{ml} \mathrm{leu-}$ peptin, and $2 \mu \mathrm{g} / \mathrm{ml}$ aprotinin). The immunoprecipitations were terminated by the addition of $30 \mu \mathrm{l} 2 \mathrm{X}$ SDS loading buffer with boiling for $5 \mathrm{~min}$. Fifty micrograms of each protein extract were separated on $10 \%$ SDSpolyacrylamide gels and transferred onto nylon membranes (Millipore, Bedford, MA, USA) with a semi-dry blotting system (Pharmacia Biotech). After blocking in $1 \mathrm{X}$ $\mathrm{PBS} / 5 \%$ non-fat dry milk/0.2\% Tween-20 at $4{ }^{\circ} \mathrm{C}$ 
overnight, the membranes were incubated with antihuman IGF-I rabbit polyclonal antibody (H-20, Santa Cruz Biotechnology, Inc., Santa Cruz, CA, USA) at a dilution of 1:200 in a blocking buffer (1X PBS/2\% non-fat dry milk $/ 0 \cdot 2 \%$ Tween-20) for $1 \mathrm{~h}$ at room temperature. The membranes were washed three times with the blocking buffer and incubated with a secondary antibody, which was conjugated with horseradish peroxidase (Amersham, Buckinghamshire, UK) at a final dilution of 1:7000. After final washes with $1 \mathrm{X}$ PBS $/ 0 \cdot 2 \%$ Tween-20, the signals were detected with ECL chemiluminescence reagents (Amersham, Buckinghamshire, UK).

\section{Serum IGF-I measurement}

Sera were collected when the mice were killed. Serum IGF-I was measured using a rat IGF-I RIA kit (DSL2900, Diagnostic Systems Laboratories, Inc., Webster, TX, USA).

\section{Histology}

Ventral, dorsolateral and anterior lobes of the prostate were separated when the mice were killed.

Haematoxylin-eosin staining Cryospecimens were fixed with $4 \%$ paraformaldehyde in PBS ( $\mathrm{pH} 7 \cdot 4)$, then stained with haematoxylin and eosin.

Immunochemistry Cryostat sections were fixed in $4 \%$ paraformaldehyde in PBS for $5 \mathrm{~min}$, rinsed with PBS (pH 7·4), then incubated with anti-human IGF-I rabbit polyclonal antibody (Santa Cruz Biotechnology, Inc.) at a dilution of 1:100, anti-mouse IGFBP-3 goat polyclonal antibody (M-19, Santa Cruz Biotechnology, Inc.) at a dilution of 1:50 or control serum overnight at room temperature. Labelling was visualized using the avidinbiotin complex method.

\section{Morphometric analysis}

Morphometry of prostatic sections was performed using a biological microscope (BX51-34, Olympus, Tokyo, Japan) with a digital camera (DP50, Olympus, Tokyo, Japan). Morphometric data were analysed using WINROOF software (Mitani Corporation, Fukui, Japan). Areas of gland, intraglandular lumen and epithelium (glandular area minus intraglandular luminal area) were measured for each gland. Area of a given lobe minus the sum of areas of each gland in the lobe in the section was regarded as the area of the interstitium. The numbers of measured individual glands in the morphometric analysis are listed in Table 1. Histograms of data of individual prostatic glands in prostatic lobes are shown in Figs 6-9.
Table 1 Numbers of measured glands in the morphometry

\begin{tabular}{|c|c|c|c|c|}
\hline & Ventral & Dorsal & Lateral & Anterior \\
\hline \multicolumn{5}{|l|}{ 14-month-old line 1} \\
\hline Non-transgenic & 52 & 37 & 37 & 10 \\
\hline Transgenic & 72 & 81 & 62 & 6 \\
\hline \multicolumn{5}{|l|}{ 17-month-old line 1} \\
\hline Non-transgenic & 68 & 73 & 16 & 7 \\
\hline Transgenic & 58 & 67 & 17 & 26 \\
\hline
\end{tabular}

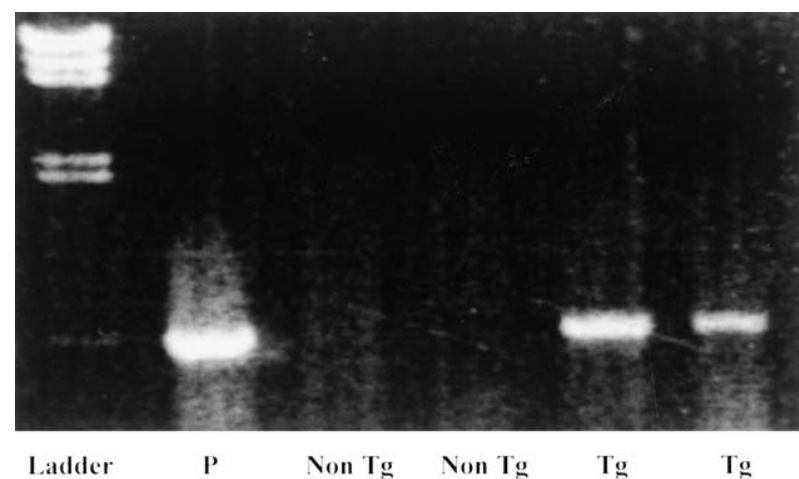

Figure 1 IGF-I transgene screening by PCR using mouse tail genomic DNA. Ladder, $\lambda$ HindIII ladder; $P$, positive control (the pBH-IGF1 vector); Non $\mathrm{Tg}$, negative transgene; $\mathrm{Tg}$, positive transgene.

Table 2 Transgene transmission into F1

\begin{tabular}{ll} 
& Transmission (\%) \\
\cline { 2 - 2 } Line & \\
Line 1 & $19 \cdot 5$ \\
Line 2 & $37 \cdot 5$ \\
Line 3 & $30 \cdot 0$ \\
Line 4 & Died before mating \\
\hline
\end{tabular}

\section{Results}

\section{Establishment of murine IGF-I transgenic mice}

Among 39 newborn C57BL/6 L mice, seven (four males and three females) were positive for the murine IGF-I transgene (Fig. 1). Transgene transmission when F0 was crossed with normal C57BL/6 L or C3H/HeN mice was as shown in Table 2. IGF-I transgenic and control littermates $\mathrm{F} 1(\mathrm{C} 57 \mathrm{BL} / 6 \mathrm{~L} \times \mathrm{C} 3 \mathrm{H} / \mathrm{HeN})$ prostates of IGF-I transgenic lines 1 and 2 were used for histological analysis.

\section{Expression of IGF-I and IGFBP-3 in murine IGF-I transgenic mice}

In 4-week-old IGF-I transgenic mouse lines 1 and 2 and their controls, IGF-I mRNA (RT-PCR) and IGF-I 


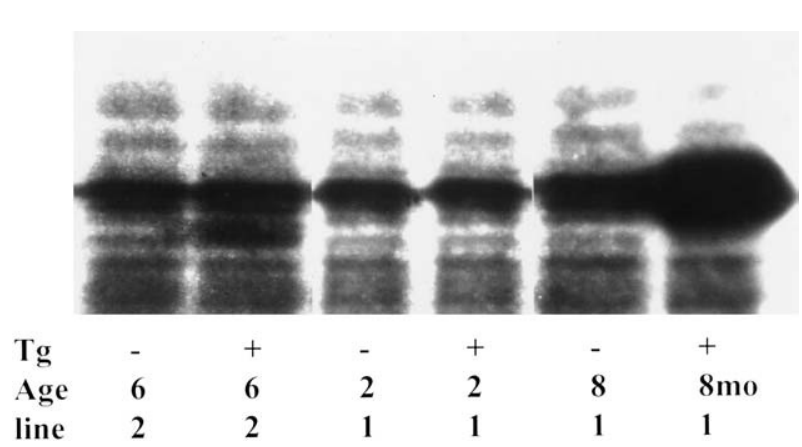

Figure 2 IGF-I protein expression in IGF-I transgenic prostates. mo, months; Tg, IGF-I transgene; line, transgenic line.

protein (immunohistochemistry) were not detected in the prostate $(n=2)$. At this age, IGF-I mRNA was detected by RT-PCR in the lung, liver and heart, but not in the intestine, kidney or testis both in IGF-I transgenic mice and in control littermates (data not shown).

As shown in Fig. 2, the level of IGF-I protein expression in the prostate of the IGF-I transgenic mouse line 1 assessed by Western blotting analysis was similar to controls at the age of 2 months, while it was enhanced compared with controls at the age of 8 months. In IGF-I transgenic mouse line 2, prostatic IGF-I protein expression was similar to controls at the age of 6 months. Serum IGF-I levels in IGF-I transgenic mice line 1 were comparable with those in controls (Fig. 3), thus IGF-I production and its action in this model could be local but not systemic.

Immunohistochemically, IGF-I was expressed in prostatic epithelial cells of ventral lobes and in epithelial basement membranes of dorsal lobes and lateral lobes of IGF-I transgenic mice (line 1), but not in those of their control littermates at 14 and 17 months of age $(n=3$ for each age, Fig. 4a). IGF-I was not detected in the anterior lobes in IGF-I transgenic mice or controls. IGF-I was slightly expressed in prostatic stromal fibroblasts of IGF-I transgenic mice (line 1) and controls. IGFBP-3 was detected in epithelial cells of prostatic ventral lobes, but not in those of dorsal, lateral or anterior lobes of IGF-I transgenic mice (Fig. 4b). In control littermates, IGFBP-3 was not detected in epithelial cells of any prostatic lobe (Fig. 4b). With respect to prostatic stroma, IGFBP-3 was observed in fibroblasts of IGF-I transgenic mice, but not in those of controls.

\section{The morphology of the prostate in murine IGF-I transgenic mice}

Macroscopic size and the appearance of prostatic lobes of IGF-I transgenic mouse lines 1 and 2 were comparable with those of their control littermates of the same age (14 and 17 months), as shown in Table 3 and Fig. 5. As shown in Fig. $4 c$, glands in ventral prostatic lobes of IGF-I transgenic mouse line 1 expressing more IGF-I than controls were more dense and enlarged similar to cysts compared with those of non-transgenic littermates. Glands and intraglandular lumens in the dorsal and lateral lobes of IGF-I transgenic mice were slightly larger than those of controls. In contrast, glands in the anterior prostatic lobe of IGF-I transgenic mouse line 1 were not morphologically different from those of non-transgenic littermates. Epithelial hyperplasia and atypism in the prostatic glands were not observed. Glands in ventral prostatic lobes and the dorsal, lateral and anterior lobes of IGF-I transgenic mouse line 2 expressing a similar amount of IGF-I as controls were not morphologically different from those of control littermates $(n=2$, data not shown).

With morphometric analysis, the areas of the lobe, gland and interstitium of IGF-I transgenic mice were not significantly different from those of controls (Table 3). Epithelial glands and intraglandular lumens in the prostatic

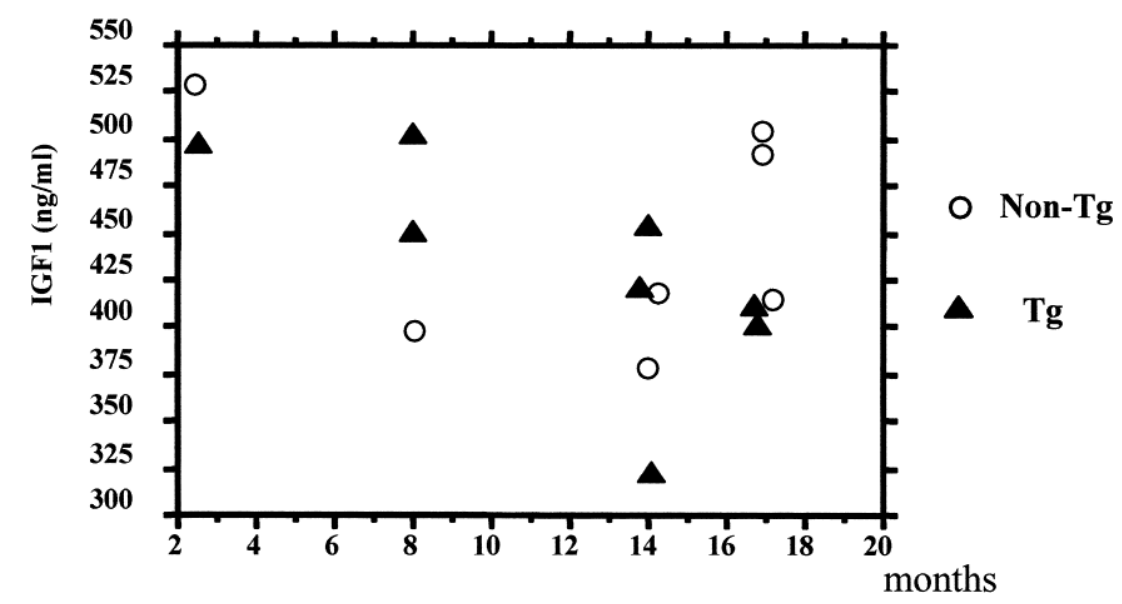

Figure 3 Serum IGF-I level in IGF-I transgenic mice line 1. Tg, transgenic; Non-Tg, non-transgenic. 


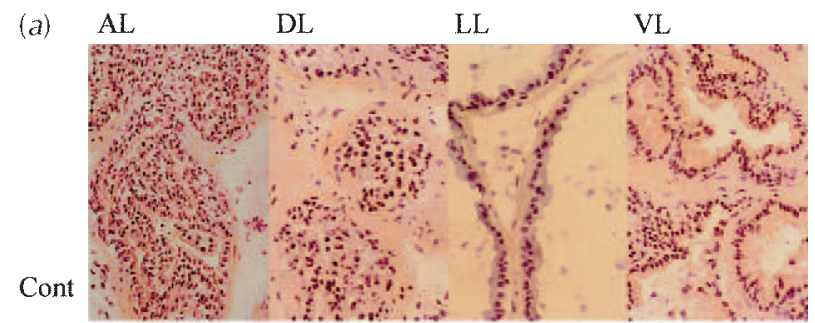

$\mathrm{Tg}$

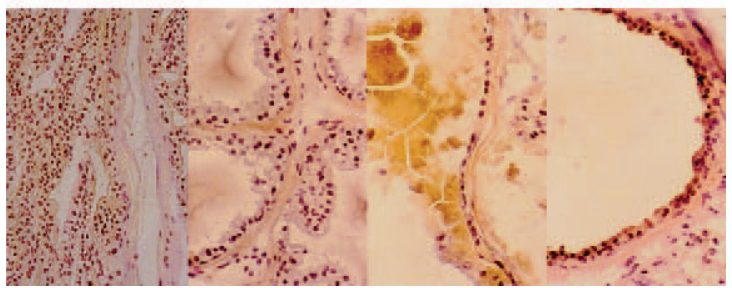

(b)

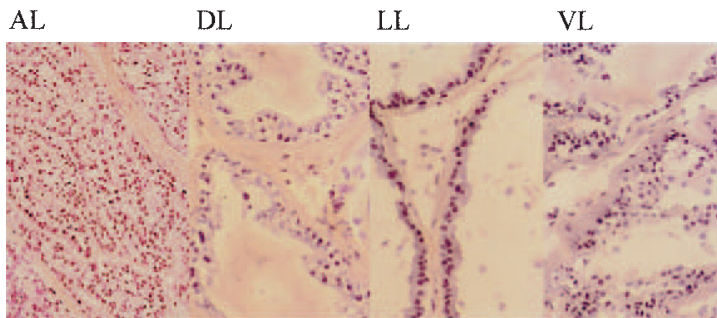

Cont

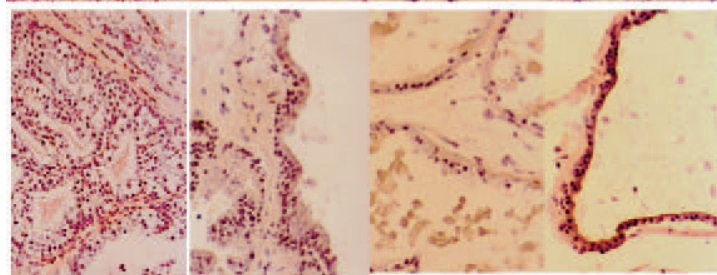

(c) $\mathrm{AL}$

DL

LL

VL

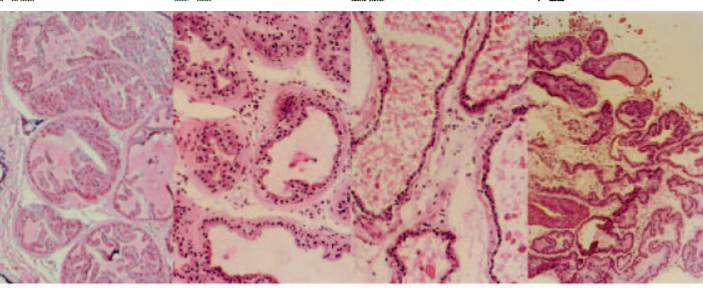

Cont

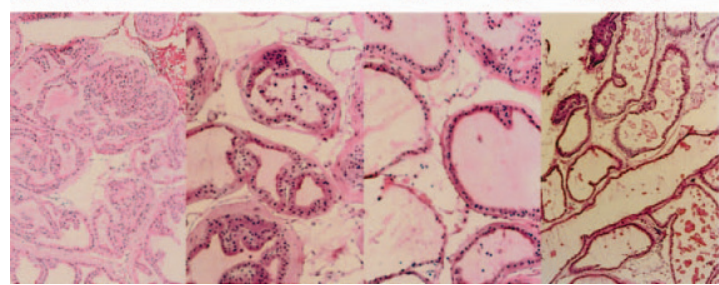

Figure 4 Histological analysis of IGF-I transgenic prostate

(line 1). (a) IGF-I expression of IGF-I transgenic prostate by immunohistological staining, $\times 100$. (b) IGFBP-3 expression of IGF-I transgenic prostate by immunohistological staining, $\times 100$. (c) Haematoxylin-eosin staining of IGF-I transgenic prostate; $\times 50$ for $\mathrm{AL}, \mathrm{DL}$ and $\mathrm{LL}$, and $\times 20$ for $\mathrm{VL}$. AL, anterior lobe; $\mathrm{DL}$, dorsal lobe; $\mathrm{LL}$, lateral lobe; $\mathrm{VL}$, ventral lobe; Cont, control (non-transgenic); $\mathrm{Tg}$, transgenic. Representative findings of mice at 17 months of age are shown.
Table 3 Areas of prostatic lobes. Median values are shown

\begin{tabular}{|c|c|c|c|c|}
\hline & & $\begin{array}{l}\text { Lobal } \\
\text { area }\end{array}$ & $\begin{array}{l}\text { Glandular } \\
\text { area }\end{array}$ & $\begin{array}{l}\text { Interstitial } \\
\text { area }\end{array}$ \\
\hline Lobe & & & & \\
\hline 14-month- & ine 1 & & & \\
\hline Ventral & Non-Tg & $6 \cdot 3$ & $4 \cdot 6$ & $1 \cdot 7$ \\
\hline & $\mathrm{Tg}$ & $9 \cdot 1$ & $6 \cdot 2$ & $2 \cdot 9$ \\
\hline Dorsal & Non-Tg & $1 \cdot 6$ & $1 \cdot 1$ & $0 \cdot 9$ \\
\hline & $\operatorname{Tg}$ & $4 \cdot 6$ & $3 \cdot 2$ & $1 \cdot 4$ \\
\hline Lateral & Non-Tg & $9 \cdot 0$ & $8 \cdot 7$ & $8 \cdot 7$ \\
\hline & $\operatorname{Tg}$ & $9 \cdot 0$ & $6 \cdot 0$ & $3 \cdot 0$ \\
\hline Anterior & Non-Tg & $5 \cdot 9$ & $3 \cdot 8$ & $2 \cdot 1$ \\
\hline & $\operatorname{Tg}$ & $5 \cdot 2$ & $5 \cdot 1$ & $0 \cdot 2$ \\
\hline 17-month-c & ine 1 & & & \\
\hline Ventral & Non-Tg & $3 \cdot 9$ & $2 \cdot 5$ & $1 \cdot 4$ \\
\hline & $\operatorname{Tg}$ & $7 \cdot 3$ & $5 \cdot 8$ & $1 \cdot 4$ \\
\hline Dorsal & Non-Tg & $2 \cdot 9$ & $1 \cdot 9$ & $0 \cdot 9$ \\
\hline & $\mathrm{Tg}$ & $2 \cdot 8$ & $2 \cdot 2$ & $0 \cdot 6$ \\
\hline Lateral & Non-Tg & $2 \cdot 5$ & $1 \cdot 6$ & $1 \cdot 0$ \\
\hline & $\operatorname{Tg}$ & $2 \cdot 7$ & $2 \cdot 2$ & $0 \cdot 6$ \\
\hline Anterior & Non-Tg & $7 \cdot 5$ & $2 \cdot 4$ & $5 \cdot 1$ \\
\hline & $\operatorname{Tg}$ & $7 \cdot 8$ & $2 \cdot 9$ & $4 \cdot 9$ \\
\hline
\end{tabular}

Non-Tg, non-transgenic; Tg, transgenic.

There was no significant difference between controls and transgenic mice by nonparametric Mann-Whitney $U$ test.
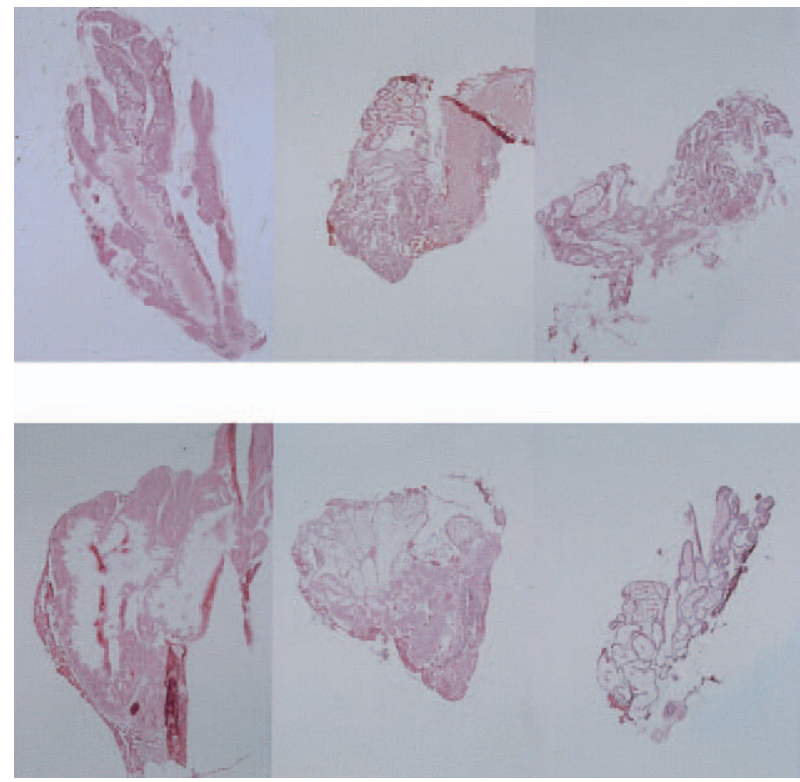

Figure 5 Haematoxylin-eosin staining of IGF-I transgenic prostate (17 months), $\times 10$. Upper panel, control; lower panel, transgenic; left, anterior lobe; middle, dorsolateral lobe; right, ventral lobe.

lobes, except the ventral lobe, were smaller at 17 months of age than at 14 months both in IGF-I transgenic mice and controls. The glandular and luminal sizes of individual glands in the ventral lobe of the IGF-I transgenic mouse line 1 were significantly larger than those of controls at 14 and/or 17 months of age, but the area of the individual 
Table 4 Areas of individual prostatic gland. Values are means \pm S.E.

\begin{tabular}{|c|c|c|c|c|c|}
\hline & & Ventral & Dorsal & Lateral & Anterior \\
\hline \multicolumn{6}{|l|}{ 14-month-old line 1} \\
\hline \multirow[t]{2}{*}{ Individual gland } & Non-Tg & $0 \cdot 15 \pm 0 \cdot 02$ & $0 \cdot 09 \pm 0 \cdot 01$ & $0 \cdot 24 \pm 0 \cdot 05$ & $0 \cdot 75 \pm 0.38$ \\
\hline & $\operatorname{Tg}$ & $0 \cdot 20 \pm 0 \cdot 04$ & $0 \cdot 12 \pm 0 \cdot 01^{*}$ & $0 \cdot 30 \pm 0.05$ & $0 \cdot 86 \pm 0 \cdot 45$ \\
\hline \multirow[t]{2}{*}{ Intraluminal } & Non-Tg & $0.09 \pm 0.02$ & $0.05 \pm 0.01$ & $0 \cdot 21 \pm 0 \cdot 05$ & $0.58 \pm 0.33$ \\
\hline & $\operatorname{Tg}$ & $0.15 \pm 0.02 *$ & $0.05 \pm 0.01$ & $0 \cdot 25 \pm 0 \cdot 05$ & $0 \cdot 66 \pm 0 \cdot 36$ \\
\hline \multirow[t]{2}{*}{ Epithelium } & Non-Tg & $0 \cdot 06 \pm 0 \cdot 00$ & $0 \cdot 07 \pm 0 \cdot 01$ & $0 \cdot 04 \pm 0 \cdot 00$ & $0 \cdot 18 \pm 0 \cdot 06$ \\
\hline & $\operatorname{Tg}$ & $0 \cdot 05 \pm 0 \cdot 00$ & $0.07 \pm 0.00$ & $0.05 \pm 0.00$ & $0 \cdot 20 \pm 0 \cdot 09$ \\
\hline \multicolumn{6}{|l|}{ 17-month-old line 1} \\
\hline \multirow[t]{2}{*}{ Individual gland } & Non-Tg & $0 \cdot 20 \pm 0 \cdot 02$ & $0 \cdot 04 \pm 0 \cdot 00$ & $0 \cdot 10 \pm 0 \cdot 02$ & $0 \cdot 29 \pm 0 \cdot 15$ \\
\hline & $\operatorname{Tg}$ & $0.29 \pm 0.03^{* *}$ & $0.06 \pm 0.00^{*}$ & $0 \cdot 18 \pm 0 \cdot 01^{*}$ & $0 \cdot 23 \pm 0.03$ \\
\hline \multirow[t]{2}{*}{ Intraluminal } & Non-Tg & $0 \cdot 10 \pm 0 \cdot 02$ & $0.01 \pm 0.00$ & $0.06 \pm 0.02$ & $0.06 \pm 0.03$ \\
\hline & $\operatorname{Tg}$ & $0 \cdot 20 \pm 0 \cdot 03^{*}$ & $0.02 \pm 0.00^{*}$ & $0 \cdot 15 \pm 0.01^{*}$ & $0.07 \pm 0.02$ \\
\hline \multirow[t]{2}{*}{ Epithelium } & Non-Tg & $0 \cdot 11 \pm 0 \cdot 01$ & $0.03 \pm 0.00$ & $0.04 \pm 0.01$ & $0 \cdot 27 \pm 0 \cdot 15$ \\
\hline & $\operatorname{Tg}$ & $0.09 \pm 0.01$ & $0.04 \pm 0.00$ & $0.03 \pm 0.00$ & $0 \cdot 15 \pm 0 \cdot 02$ \\
\hline
\end{tabular}

Non-Tg, non-transgenic; $\mathrm{Tg}$, transgenic.

${ }^{*} P<0.01$ compared with non-transgenic, ${ }^{* *} P<0.03$ compared with non-transgenic by unpaired t-test.

\section{Ventral Lobe}
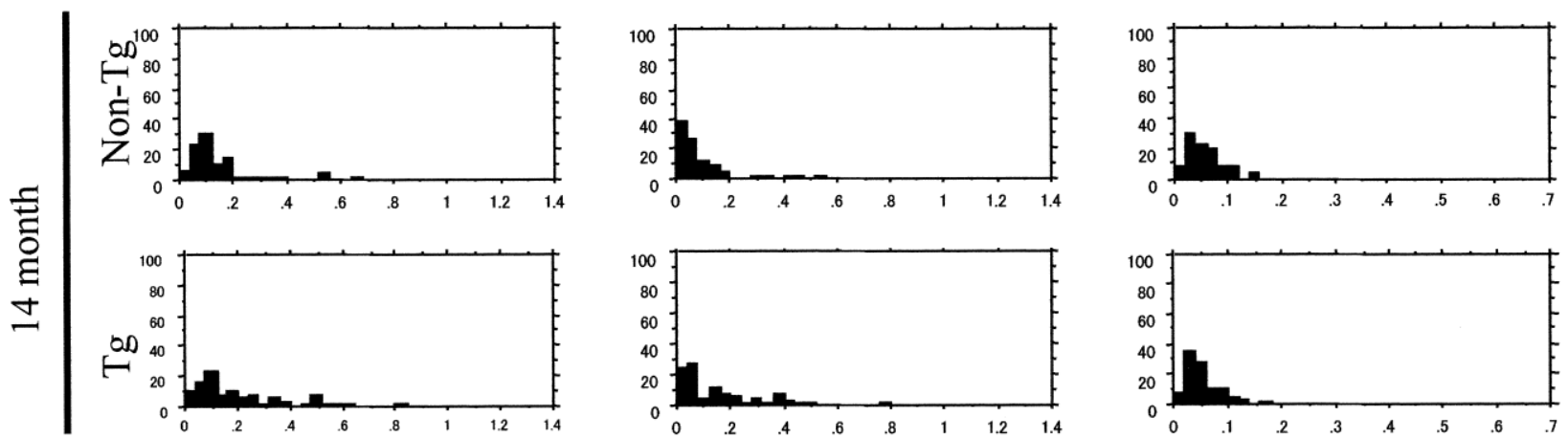

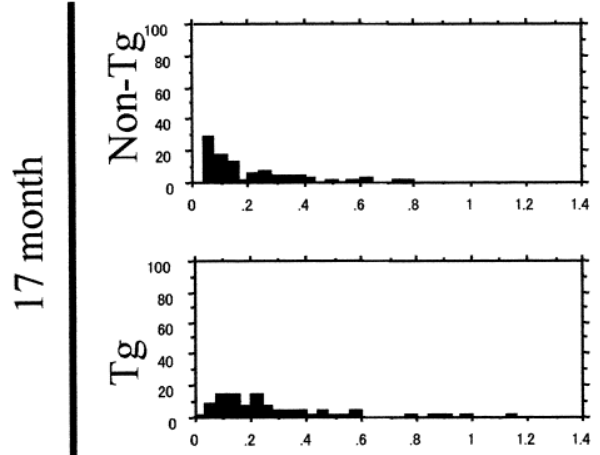

Glandular area
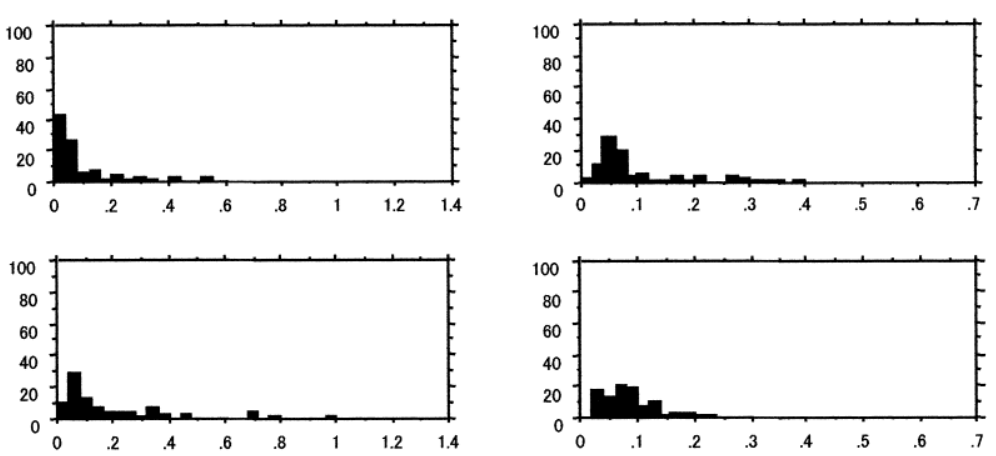

Luminal area

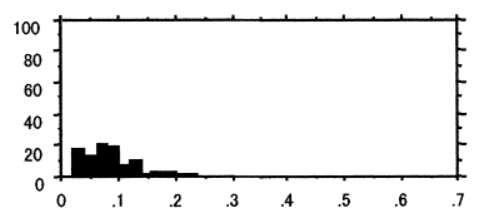

Epithelial area

Figure 6 Histograms of individual glandular, luminal and epithelial areas in the prostatic ventral lobe. $\mathrm{Tg}$, transgenic; Non- $\mathrm{Tg}$, non-transgenic; vertical axis, \%; horizontal axis, area $\left(\mu \mathrm{m}^{2}\right)$. 


\section{Dorsal Lobe}
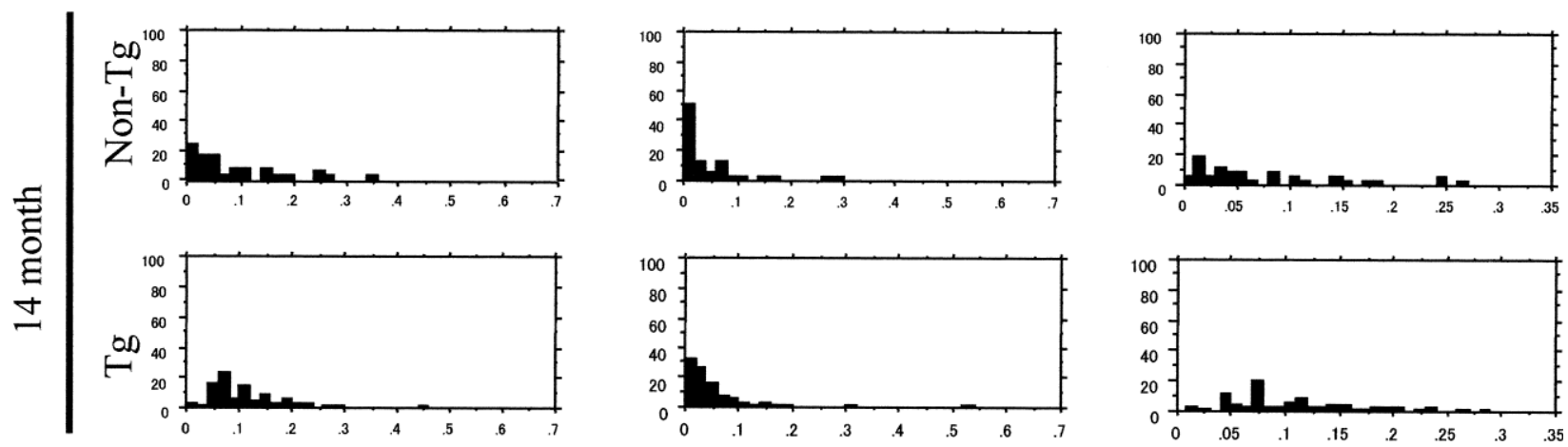

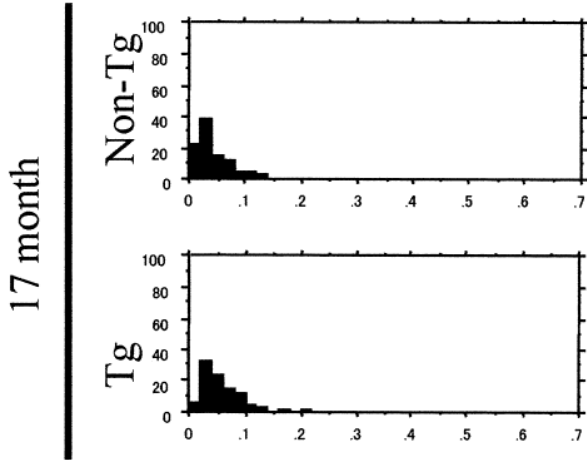

Glandular area
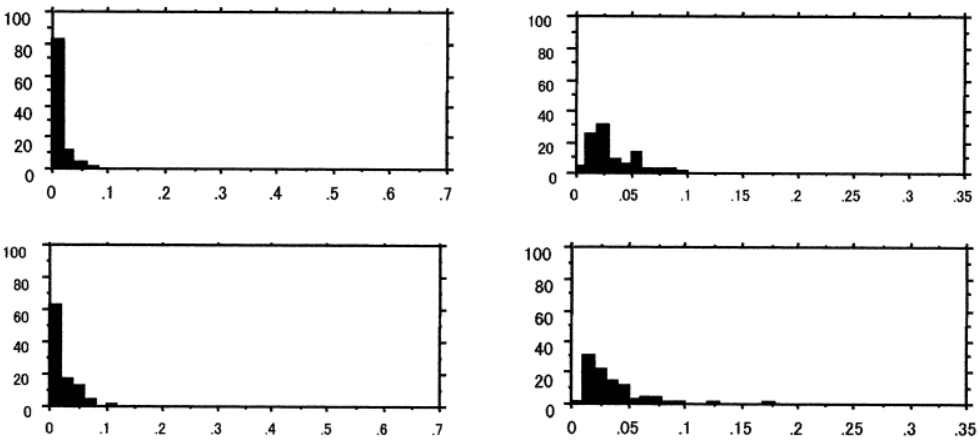

Luminal area

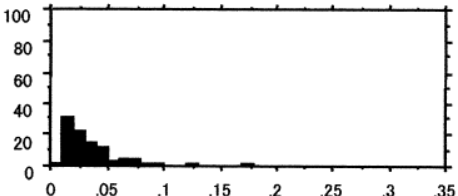

Epithelial area

Figure 7 Histograms of individual glandular, luminal and epithelial areas in the prostatic dorsal lobe. Tg, transgenic; Non-Tg, non-transgenic; vertical axis, \%; horizontal axis, area $\left(\mu \mathrm{m}^{2}\right)$.

glandular epithelium was similar to the controls (Table 4 and Fig. 6). The individual glandular size of the dorsal and lateral lobes of IGF-I transgenic mouse line 1 was also larger than that of controls at 14 and/or 17 months (Table 4 and Figs 7 and 8). The individual glandular size, luminal size and epithelial area in the anterior lobe of IGF-I transgenic mouse line 1 were similar to the controls. The glandular size, luminal size and epithelial area of individual glands in the ventral lobe of IGF-I transgenic mouse line 2 were comparable with those of control mice (data not shown).

\section{Statistical analysis}

Unpaired $t$-test and Mann-Whitney $U$ test were used for statistics. $P<0.05$ was taken as significant.

\section{Discussion}

In the present IGF-I transgenic prostate overexpressing IGF-I protein, the epithelial glands and their lumens were more dense and enlarged in prostatic ventral lobe microscopically and by morphometric analysis. Epithelial glands of the prostatic dorsal and lateral lobes of the transgenic line were slightly larger than those of controls microscopically. Morphometric analysis also found that their glandular and luminal sizes were significantly larger than those of controls.

In the IGF-I transgenic prostate of line 2, which did not overproduce IGF-I compared with control non-transgenic prostate, epithelial glands of the prostatic lobes were microscopically similar to controls. Thus, the changes observed in the ventral, dorsal and lateral lobes of line 1 mice overproducing IGF-I in the prostate may be because of overproduced IGF-I. There may be no morphological changes in the anterior lobe, as the glandular epithelium in the anterior lobe did not produce IGF-I.

Most significant morphological changes were observed in the prostatic ventral lobes of IGF-I transgenic mice. Since we did not perform precise quantitation of IGF-I in individual lobes, there may have been differences in the IGF-I levels among individual prostatic lobes. IGFBP-3 was detected only in the ventral lobes, not in the 


\section{Lateral Lobe}
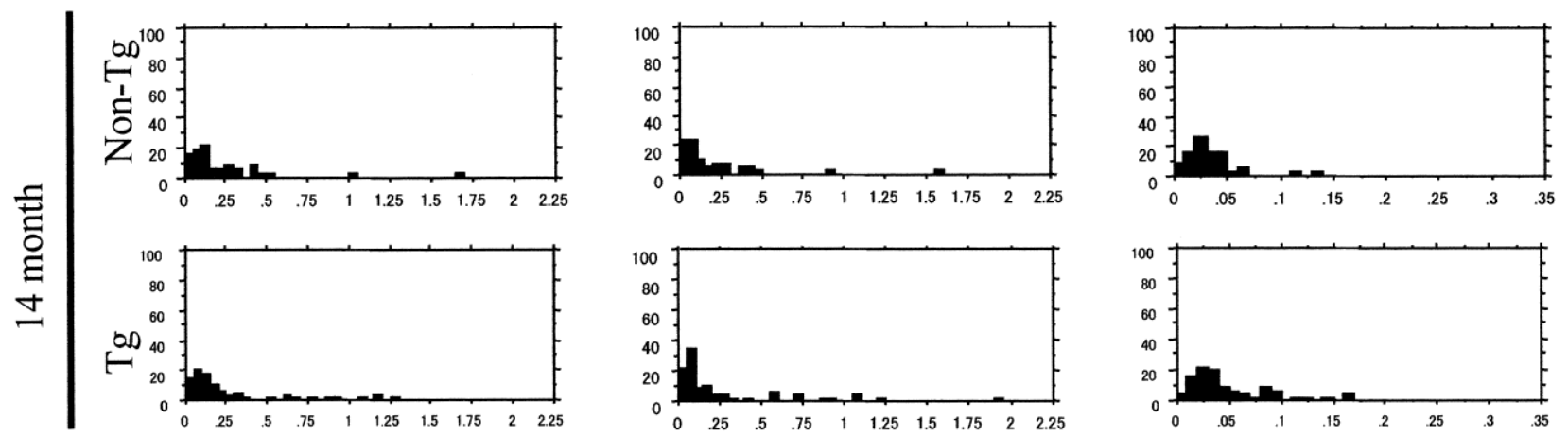

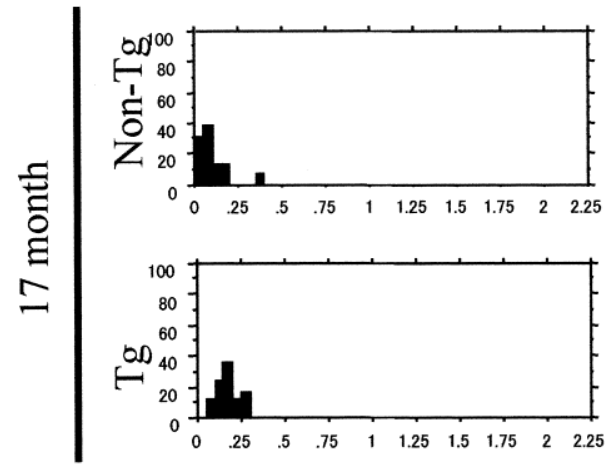

Glandular area
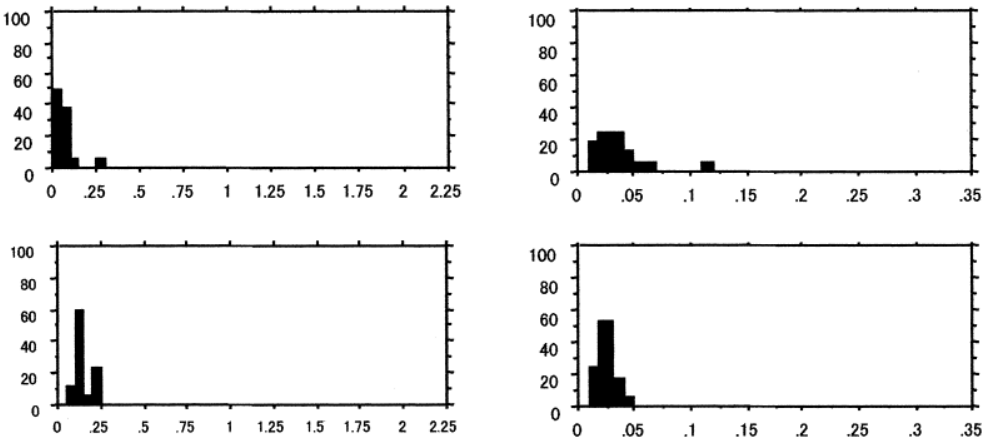

Luminal area

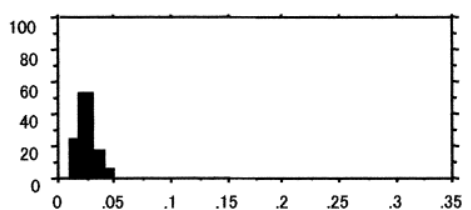

Epithelial area

Figure 8 Histograms of individual glandular, luminal and epithelial areas in the prostatic lateral lobe. Tg, transgenic; Non-Tg, non-transgenic; vertical axis \%; horizontal axis, area $\left(\mu \mathrm{m}^{2}\right)$.

dorsal, lateral or anterior lobes of IGF-I transgenic mice. Considering that IGFBP-3 is inhibitory to the mitogenic action of IGF-I in some circumstances, IGFBP-3 expression in the transgenic ventral lobes alone may be compensatory for more IGF-I expression in the transgenic ventral lobes than the transgenic dorsal, lateral or anterior lobes. Another possibility may be that the ventral lobe may be more sensitive to IGF-I than other lobes and may modulate expression of IGFBP-3. There is also a possibility that IGF-I and IGFBP-3 expression in the ventral lobe of IGF-I transgenic mice are independent.

The morphology of a prostatic duct changes markedly between the tip and the urethral opening, and there is a possibility that glands close to or far from the urethra can be chosen in one section. Histograms (Figs 6-9) created with glands in these sections may be appropriate for showing the rightward-shift pattern of individual glandular and luminal size in the ventral, dorsal and lateral lobes.

DiGiovanni et al. (2000) reported that transgenic IGF-I expression led to activation of the IGF-I receptor and spontaneous tumorigenesis in prostate epithelium such as hyperplasia, atypical hyperplasia, prostatic intraepithelial neoplasia, and finally adenocarcinoma in prostatic dorsolateral and ventral lobes in mice by 6 months of age. Differences between the present findings and those reported by DiGiovanni may be due to the extent of IGF-I production in the transgenic prostate. IGF-I production in the present IGF-I transgenic mouse line 1 was two- to threefold greater than that in controls. This may not be enough to lead to more profound epithelial hyperplasia and malignancy. In the present study, prostatic glands in the ventral, dorsal and lateral lobes did not show enhanced epithelial growth or epithelial neoplastic changes, but prostatic glandular enlargement was obvious. Thus, IGF-I might have stimulated fluid secretion into intraglandular lumens from prostatic glandular epithelium of the prostatic ventral lobes and to a lesser extent the lateral dorsal lobes in IGF-I transgenic mice. The follicle of polycystic ovary syndrome has characteristic IGF family expression, supporting an intraovarian role for IGF family in ovarian follicle growth, steroidogenesis and atresia (Giudice 1999).

According to our unpublished findings, FGF-2 (basic FGF) transgenic mice under the control of rat probasin 


\section{Anterior Lobe}
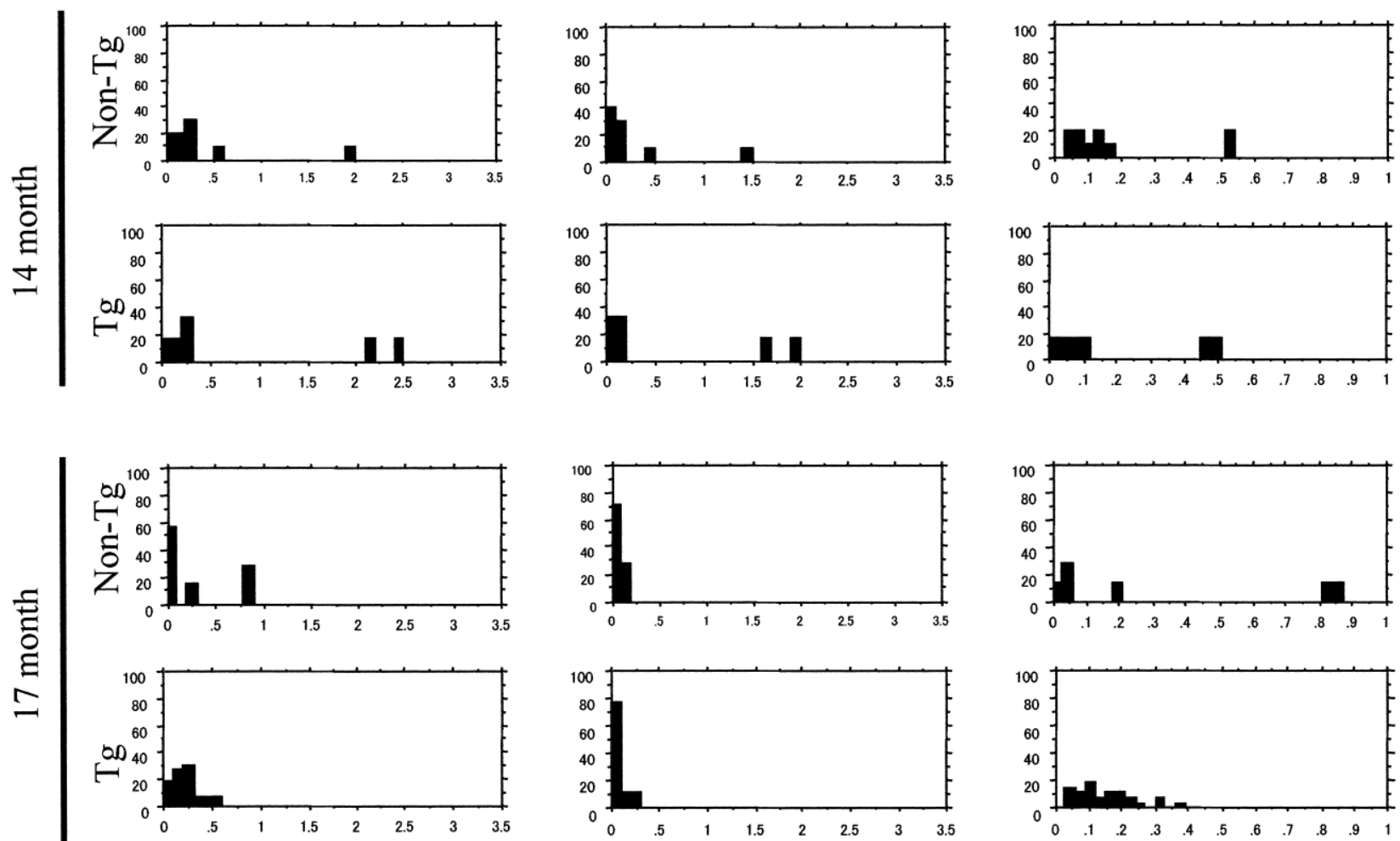

Glandular area
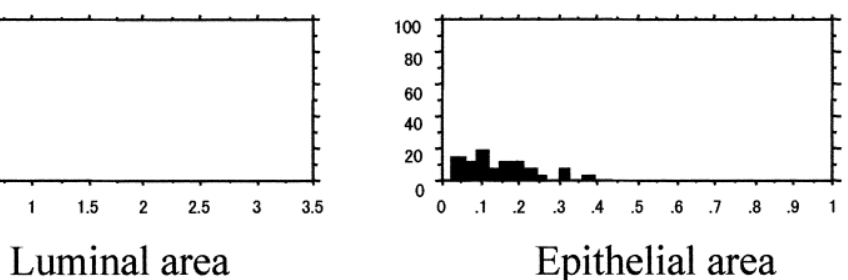

Epithelial area

Figure 9 Histograms of individual glandular, luminal and epithelial areas in the prostatic anterior lobe. Tg, transgenic; Non-Tg; non-transgenic; vertical axis, \%; horizontal axis, area $\left(\mu \mathrm{m}^{2}\right)$.

promoter expressing FGF-2 in the prostate showed simple epithelial hyperplasia in the dorsal lobe of the prostate, but not in the lateral and anterior lobes. This may also support a prostatic lobal difference in the sensitivity to given growth factors. In conclusion, IGF-I transgenic mice under the control of rat probasin promoter showed more dense and enlarged epithelial glands in their prostatic ventral, dorsal and lateral lobes.

\section{Acknowledgements}

pBH500 containing rat probasin promoter gene was provided by Dr R J Matusik (Vanderbilt University, Nashville, TN, USA). The mammalian expression vector pCAGGS was provided by Dr J Miyazaki (Osaka University, Osaka, Japan). We are grateful to Dr Nomura for assistance in histology.

\section{References}

Chan JM, Stampfer MJ, Giovannucci E, Gann PH, Ma J, Wilkinson P, Hennekens CH \& Pollak M 1998 Insulin-like growth
factor-I and prostate cancer risk: a prospective study. Science $\mathbf{2 7 9}$ 563-566.

DiGiovanni J, Kiguchi K, Frijhoff A, Wilker E, Bol DK, Beltran L, Moats S, Ramirez A, Jorcano J \& Conti C 2000 Deregulated expression of insulin-like growth factor 1 in prostate epithelium leads to neoplasia in transgenic mice. PNAS 97 3455-3460.

Djavan B, Waldert M, Seitz C \& Marberger M 2001 Insulin-like growth factors and prostate cancer. World Journal of Urology 19 225-233.

Foster BA, Kaplan PJ \& Greenberg NM 1998 Peptide growth factors and prostate cancer: new models, new opportunities. Cancer and Metastasis Reviews 17 317-324.

Giudice LC 1999 Growth factor action on ovarian function in polycystic ovary syndrome. Endocrinology and Metabolism Clinics of North America 28 325-339.

Kaplan PJ, Mohan S, Cohen P, Foster BA \& Greenberg NM 1999 The insulin-like growth factor axis and prostate cancer: lessons from the transgenic adenocarcinoma of mouse prostate (TRAMP) model. Cancer Research 59 2203-2209.

Niwa H, Yamamura K \& Miyazaki J 1991 Efficient selection for high-expression transfectant with a novel eukaryotic vector. Gene 108 193-199.

Rennie PS, Bruchovsky N, Leco KJ, Sheppard PC, McQueen SA, Cheng H, Snoek R, Hamel A, Bock ME, MacDonald BS et al. 1993 Characterization of two cis-acting DNA elements involved in the androgen regulation of the probasin gene. Molecular Endocrinology $723-36$. 
Ruan W, Powell-Braxton L, Kopchick JJ \& Kleinberg DL 1999 Evidence that insulin-like growth factor I and growth hormone are required for prostate gland development. Endocrinology 140 1984-1989.

Takeuchi T, Ueki T, Nishimatsu H, Kajiwara T, Ishida T, Jishage K, Ueda O, Suzuki H, Li B, Moriyama N \& Kitamura T 1999

Accelerated rejection of Fas-ligand expressing heart grafts. Journal of Immunology 162 518-522.
Wennbo H, Kindblom J, Isaksson OG \& Tornell J 1997 Transgenic mice overexpressing the prolactin gene develop dramatic enlargement of the prostate gland. Endocrinology 138 4410-4415.

Received 21 January 2003

Accepted 28 February 2003 